\title{
The science of cycology: Failures to understand how everyday objects work
}

\author{
REBECCA LAWSON \\ University of Liverpool, Liverpool, England
}

\begin{abstract}
When their understanding of the basics of bicycle design was assessed objectively, people were found to make frequent and serious mistakes, such as believing that the chain went around the front wheel as well as the back wheel. Errors were reduced but not eliminated for bicycle experts, for men more than women, and for people who were shown a real bicycle as they were tested. The results demonstrate that most people's conceptual understanding of this familiar, everyday object is sketchy and shallow, even for information that is frequently encountered and easily perceived. This evidence of a minimal and even inaccurate causal understanding is inconsistent with that of strong versions of explanation-based (or theory-based) theories of categorization.
\end{abstract}

I think I know less than I thought.

-Participant's comment, after completion of the bicycle drawing task

Recent research has suggested that people often overestimate their ability to explain how things function. Rozenblit and Keil (2002) found that people overrated their understanding of complicated phenomena. This illusion of explanatory depth was not merely due to general overconfidence; it was specific to the understanding of causally complex systems, such as artifacts (crossbows, sewing machines, microchips) and natural phenomena (tides, rainbows), relative to other knowledge domains, such as facts (names of capital cities), procedures (baking cakes), or narratives (movie plots). Rozenblit and Keil (2002; see also Mills \& Keil, 2004) investigated why people overestimated their knowledge and which factors changed their ratings when they were confronted with evidence of the inadequacy of their understanding. Rozenblit and Keil found that people reduced their estimation of their own knowledge after having to provide functional explanations. Similarly, studies of naive physics have demonstrated that adults' understanding of mechanics (e.g., trajectories of falling objects and displacement of liquids; Kaiser, Proffitt, Whelan, \& Hecht, 1992) and optics (e.g., mirrors; Bertamini, Spooner, $\&$ Hecht, 2003) is often sketchy, inaccurate, and inconsis-

This research was supported by Grant RES-000-27-0162 from the Economic and Social Research Council. Thanks to Tom Mortensen and Julian Todd for the original inspiration for these studies, to the Liverpool Visual Perception Lab Group for helpful discussions, and to the volunteer participants from University Open Days, the Merseyside Cycle Campaign, the Liverpool Wheelers, the Cambridge University Caving Club, and the Red Rose Cave and Pothole Club. Correspondence should be addressed to R. Lawson, School of Psychology, University of Liverpool, Eleanor Rathbone Building, Bedford Street South, Liverpool L69 7ZA, England (e-mail: rlawson@liverpool.ac.uk). tently applied. Together, these results demonstrate weaknesses in people's understanding of everyday objects and events, and they appear to provide evidence against explanation-based (or theory-based) theories of categorization (Murphy, 2002; Murphy \& Medin, 1985).

Explanation-based theories assume that conceptual knowledge is represented like scientific theories in that concepts are causally related to each other and that explanations underlie what can be directly observed (Ahn \& Luhmann, 2005). Murphy and Medin (1985) and, from developmental research, Carey (1985) and Keil (1989), have proposed that our concepts are our ways of explaining the world to ourselves and others. Explanation-based theories contrast with similarity-based theories of categorization (prototype and exemplar theories), which assume that there is some simpler means of categorizing stimuli on the basis of similarity clusters in an internal representational space (Murphy, 2002). Explanation-based theories instead suggest that features of concepts are related to each other (often causally) within structured internal representations. These more complex representations incorporate our general knowledge of the world and our intuitive theories about which aspects of a stimulus are most important when we are judging similarity (e.g., causal vs. superficial features). Concepts are thus not merely lists of independent features but rather include an "explanation" of the appearance, function, and other aspects of exemplars of that concept. It is important to note that most proponents of explanationbased theories emphasize that these "theories" are informal explanations of the world and generally are not fully coherent, organized, scientific accounts (Murphy, 2002).

Under certain circumstances, background knowledge has been found to influence concept acquisition and categorization performance (Lin \& Murphy, 1997; Murphy, 2002; Pazzani, 1991; Wisniewski, 1995). Nevertheless, this information may not be routinely available to us (Smith \& 
Sloman, 1994). In particular, if our causal understanding of familiar and relatively simple objects is scanty or inaccurate - as Rozenblit and Keil's (2002) results suggest - then this knowledge may not be a central component of our concepts. Instead, a well specified similarity-based model of categorization may provide a better account of our normal conceptual processes than explanation-based theories do.

Keil and Wilson (Keil, 2003b; Wilson \& Keil, 2000), however, have argued that the finding that people have an illusion of explanatory depth (Rozenblit \& Keil, 2002) is not necessarily inconsistent with explanation-based theories, even though such theories assume that causal and functional knowledge underpin our concepts. Keil (2003b) has suggested that, even if our understanding of how objects function is fragmentary and shallow, it may be sufficient to track the causal structure of the world. Furthermore, this minimal understanding would benefit us by not overburdening our limited information-processing and information-storage capacities.

Rozenblit and Keil (2002) focused on subjective measures of people's knowledge of objects and phenomena. Their primary measure was the change in a person's selfratings of the quality of his or her written functional explanations. In order to extend their findings, in the present study I focused on measuring people's objective understanding of everyday objects by asking them to draw object parts and to answer forced-choice questions about object function. This study assessed people's understanding of the functioning of a familiar and relatively simple object: the bicycle. The bicycle was selected for two reasons. First, Rozenblit and Keil predicted that mechanical objects with visible parts would produce a greater overestimation of understanding than would electrical artifacts (like computers) with hidden parts. They suggested that people may mistake being able to see the mechanism of an object (as is the case for bicycles, zippers, and can openers) with being able to understand how the object itself works. Second, bicycles are familiar, everyday objects. In the present studies, of those participants who claimed to never cycle or to only rarely cycle $(n=193), 97 \%$ had learned to cycle and $45 \%$ owned a bicycle. Additionally, most British people frequently see bicycles parked and being ridden.

The present study investigated the level of detail and the accuracy of the information that people have about how bicycles work. If people's causal explanations are indeed central to their conceptual knowledge, then they should know how important parts of a bicycle are causally related. Note that this information is distinct from (and may be independent of) the motor knowledge necessary to actually ride a bicycle. The explanation-based approach to conceptual knowledge assumes that people have informal theories about all their concepts (e.g., snakes, volcanoes, nests), not just those artifacts that they use in their everyday lives. Motor knowledge may include only minimal causal information. For example, to ride a bicycle we need to know that pushing the top pedal forward and down drives us forward; we do not have to know how the pedal movement is transformed into the motion of the bicycle (i.e., the roles of the chain and the back wheel). Also, perceptual information acquired online probably underpins people's ability to ride a bicycle: People who rarely cycle may rely on seeing and feeling the bicycle to support their motor performance. Well designed man-made artifacts have affordances and physical constraints that help to specify how they are to be used (Norman, 2002). Although we may be able to deduce how a bicycle works by looking at it, this information may not be stored as part of our conceptual knowledge of bicycles.

\section{EXPERIMENT 1 Nonexperts Who Were Not Told What the Study Was Testing}

\section{Method}

Participants. Eighty-one unpaid volunteers were tested in three groups. They were prospective psychology students, their parents who had come to the University of Liverpool for an Open Day, and psychology undergraduates. Most participants either rarely cycled (31\%) or never cycled (49\%).

Materials and Procedure. The participants were given a single sheet of A4 $(210 \mathrm{~mm} \times 297 \mathrm{~mm})$ paper, folded in half. The bicycle drawing task (see Figure 1) and the forced-choice task (see Figure 2) were on the top and bottom of the first side, respectively, and a questionnaire was on the other side. First, the participants were asked to rate their functional knowledge of bicycles on a scale from 1 ("I know little or nothing about how bicycles work") to 7 ("I have a thorough knowledge of how bicycles work"). Next, they were asked to draw the pedals, chain, and extra frame onto a sketch of a bicycle (see Figure 1). Then, they were asked to select which of four alternative pictures was correct for the bicycle frame, pedals, and chain (see Figure 2). This checked that drawing errors were not merely due to problems sketching or to scoring drawing errors. Finally, the participants were asked to rerate their functional knowledge of bicycles and fill out a questionnaire about their age, gender, and experience with bicycles. The study took 5-10 min to complete. The participants were given the bicycle questionnaire without being told what was being investigated.

Three types of errors, each of which would have severely impaired the functioning of a bicycle (see Figure 3 for examples), were recorded in the drawings:

Frame errors: drawing the frame joining the front and back wheels, making steering impossible.

Pedal errors: failing to draw the pedals between the wheels and inside the chain so the pedals could not drive the chain (if the pedals were separated from the chain, see Figure 3B, or were omitted) or rendered the chain unnecessary (if the pedals were drawn attached to the center of the front or back wheel, see Figures 3A and 3D). These errors often also meant that cyclists would find it difficult to reach the pedals with their feet.

Chain errors: failing to draw the chain around the pedals and the back wheel. In most errors the chain was depicted looped around both the front wheel and the back wheel. This design would require the chain to stretch when the cyclist was steering.

In the forced-choice task, the correct responses were first for the frame, second for the pedals, and fourth for the chain (see Figure 2). All other responses were errors.

\section{Results}

Over $40 \%$ of nonexperts made at least one error in both the drawing and the forced-choice tasks (see Table 1). In this and the subsequent experiments, error scores were almost as high on the forced-choice task as on the freehand drawing task, indicating that production problems were not the primary cause of people's deficiencies (Kaiser 
First, please can you rate your knowledge of how bicycles work on a scale from 1 to 7 where 1 means "I know little or nothing about how bicycles work" and 7 means "I have a thorough knowledge of how bicycles work". You do not need to be an expert to give yourself a "7" rating —an expert would be rated as 7++. Also, you should rate how much you know, not how much you think you know compared to other people. Rating:
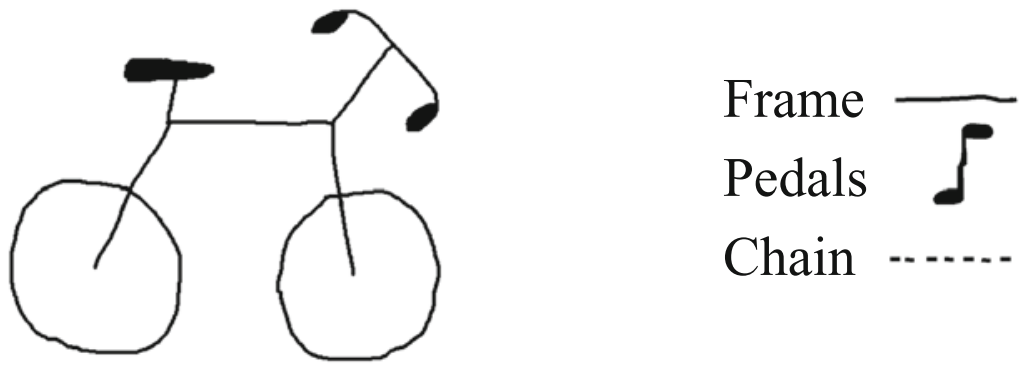

Chain .......

Second, as best you can, please fill in on the above schematic bicycle drawing the main bits of the frame of the bicycle that you think are missing, the pedals and the bicycle chain. Use the symbols given on the right of the drawing to show the frame, pedals and chain.

Figure 1. Response sheet for bicycle drawing task.

et al., 1992; Nobes, Martin, \& Panagiotaki, 2005). Some posttest comments were "I think context matters, I know a bike when I see it but it's different to recall [it] when sat in a room"; "Thinking about it in more detail, I realised I had no idea about its structure"; "I can’t believe I found it so difficult to remember what a bike frame looks like!"; "I thought I knew more about the workings than I actually did"; "It's hard to picture a bicycle when you have to"; "I did not think long enough about the front wheel turning"; and "I never knew how little I knew about things until I had to draw them."

Results from naive physics have shown that when people are given more lifelike alternatives, their ability to discriminate unnatural from realistic situations can im-

3. CIRCLE which one of these four bicycles best shows the usual position of the frame:
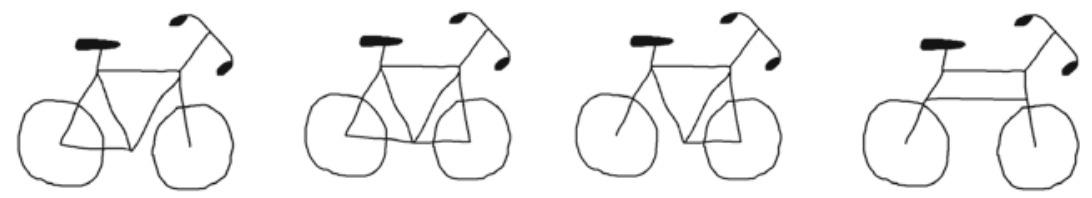

4. CIRCLE which one of these four bicycles best shows the usual position of the pedals:
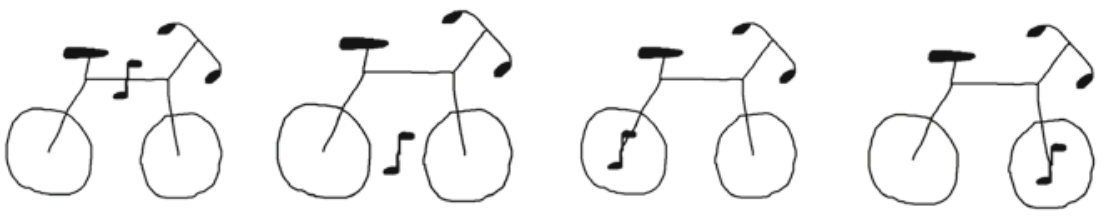

5. CIRCLE which one of these four bicycles best shows the usual position of the chain:
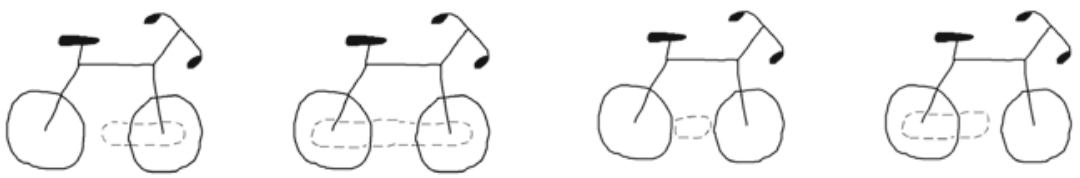

Figure 2. Questions for forced-choice task. Correct responses: frame = first bicycle; pedals $=$ second bicycle; chain $=$ fourth bicycle. 
(A) Male

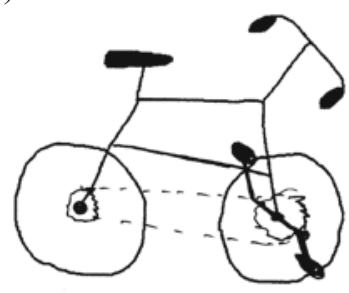

(C) Female

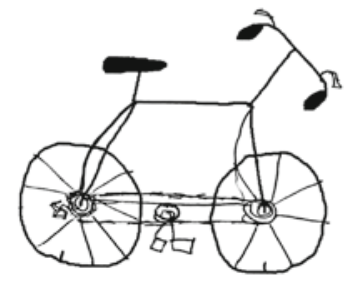

(B) Female

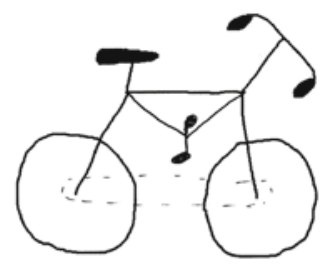

(D) Male

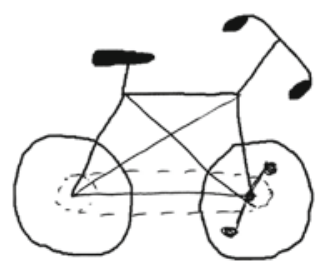

Figure 3. Four drawings from the bicycle drawing task (see Figure 1). Drawings show pedal and chain errors in (A) and (B), frame and chain errors in (C), and the rare triple combination of frame, pedal, and chain errors in (D). The four participants stated that they (A) cycled at least once a month, (B) never cycled, (C) cycled most days, and (D) rarely cycled.

prove (Bertamini et al., 2003; Kaiser et al., 1992), but this is not always observed (Proffitt, Kaiser, \& Whelan, 1990; Rohrer, 2003). The perceptual realism manipulation in the naive physics studies is similar to that which was used in the drawing compared with forced-choice tasks here. Participants continued to make many errors when they were shown pictures of possible bicycles in the forcedchoice task. Thus, participants could not remember what a bicycle looked like, even when they were prompted with perceptually realistic pictures.

\section{EXPERIMENT 2 Nonexperts Informed That Their Functional Knowledge Was Being Tested}

In Experiment 2, 94 participants-from the same population as Experiment 1 -were tested in two groups. Most participants either rarely cycled $(27 \%)$ or never cycled (54\%). Experiment 2 replicated Experiment 1, except that in Experiment 2 participants were informed that their functional knowledge of bicycles was going to be investigated. Participants might have made drawing errors in Experiment 1 because they were concentrating on producing well drawn pictures rather than focusing on drawing functionally viable bicycles. To address this possibility, participants in Experiment 2 were given a heavy and rather patronizing hint about what the task was going to be about before they began. I told them, "I am not interested in your drawing ability. It does not matter if your lines are wobbly or whatever. What I am interested in is what you know about how bicycles work. I want to make you think about what the pedals of the bike do ... and what the chain of the bike does ... and why the frame of the bike is a particular shape ... and how you steer a bike. So I want you to think about how a bike works before you draw in the parts."

Surprisingly, this hint did not reduce errors in Experiment 2 (see Table 1). Indeed, in comparison with Experiment 1, more participants in Experiment 2 made at least

Table 1

Percentage Errors in the Bicycle Drawing and Forced-Choice Tasks

in Experiments 1, 2, and 3 for Each Error Type (Frame, Pedals, and Chain) and Then If at Least 1 Error Occurred in Any of the Three Error Types

\begin{tabular}{|c|c|c|c|c|c|c|}
\hline \multirow[b]{2}{*}{ Error Type } & \multicolumn{2}{|c|}{ Experiment 1} & \multicolumn{2}{|c|}{ Experiment 2} & \multicolumn{2}{|c|}{ Experiment 3} \\
\hline & Drawing & Forced Choice & Drawing & Forced Choice & Drawing & Forced Choice \\
\hline Frame & 12 & 26 & 23 & 46 & 3 & 7 \\
\hline Pedals & 7 & 4 & 11 & 5 & 4 & 1 \\
\hline Chain & 36 & 28 & 50 & 43 & 6 & 9 \\
\hline Any & 44 & 40 & 60 & 55 & 9 & 13 \\
\hline
\end{tabular}

Note-In Experiment 1, participants $(N=81)$ were nonexperts given no hints about the task. In Experiment 2, participants $(N=94)$ were nonexperts told to focus on function. In Experiment 3, participants $(N=68)$ were cycling experts given no hints about the task. 
one drawing error $\left[\chi^{2}(1, n=175)=3.99, p<.05\right]$ and at least one forced-choice error $\left[\chi^{2}(1, n=175)=4.36\right.$, $p<.05]$. These increased error rates can largely be explained by the higher proportion of females tested in Experiment 2 , as discussed below.

\section{EXPERIMENT 3 \\ Cycling Experts Who Were Not Told What the Study Was Testing}

The results of the first two experiments revealed that nonexperts made many fundamental mistakes when they tried to show how bicycles worked, even when they were told what I was investigating. I was concerned that this poor performance might simply be due to the difficulty of the task. Experiment 3 replicated the results of Experiment 1, but it tested 68 cycling experts to determine whether frequent use of bicycles would lead to a reduction in error rates. Of these experts, 31 were tested together at the Merseyside Cycle Campaign's Annual General Meeting and 37 were tested individually or in groups of up to 10. Most cycled frequently, and $88 \%$ cycled at least weekly.

Experts made far fewer errors than nonexperts (see Table 1), though they were not perfect. Relative to those tested in Experiment 1, many fewer experts made drawing errors $\left[\chi^{2}(1, n=149)=23.17, p<.001\right]$ or forcedchoice errors $\left[\chi^{2}(1, n=149)=12.79, p<.001\right]$. Thus, when participants had sufficient expertise with a bicycle, performance was generally good; so, the task was not too difficult or confusing per se. Note, though, that the assumption behind explanation-based theories is that causal information is central to all our concepts and not just for a handful of objects for which we have large amounts of experience. The accurate performance of bicycle experts in Experiment 3 demonstrated that the task was not hard per se. Therefore, the poor performance of nonexperts in Experiments 1 and 2 suggests that most people do not have a basic understanding of how bicycles work. ${ }^{1}$

\section{Self-Ratings of Understanding of Bicycle Function}

Not surprisingly, the experts in Experiment 3 rated their bicycle knowledge higher than the nonexperts in Experiments 1 and $2[F(2,224)=14.02, p<.001$; see Table 2]. Posttest ratings were lower than pretest ratings in Experi- ments 1 and 2 (though this difference was not significant) and were higher in Experiment $3[F(1,59)=9.142, p<$ $.005]$. Thus, participants tended to alter their ratings depending on whether they did poorly on the bicycle tasks (in Experiments 1 and 2) or were accurate (in Experiment 3), consistent with Rozenblit and Keil's (2002) findings. This suggests that participants had some insight into their own performance. However, the small size of these differences - both across and within studies - suggests that these self-ratings only crudely measured changes in participants' metaknowledge. This is consistent with research showing that people are generally inaccurate at assessing their own knowledge and abilities, particularly in domains for which it is difficult to assess personal performance, such as in the provision of explanations (Dunning, Johnson, Ehrlinger, \& Kruger, 2003; Mabe \& West, 1982). Supporting this hypothesis, participants' pretest and posttest self-ratings of their knowledge of bicycle function did not correlate highly to their actual knowledge, as assessed by the total errors that they made in the task (see Table 2), though all correlations were significant $(p<.05)$.

\section{Sex, Age, and Expertise Effects}

An unanticipated finding in the present studies was a striking difference in performance between men and women (see Table 3). For the nonexperts in Experiments 1 and 2, men made only about one third the errors that women made. This male advantage was significant in Experiment 1 for both drawing errors $\left[\chi^{2}(1, n=80)=\right.$ $15.20, p<.001]$ and forced-choice errors $\left[\chi^{2}(1, n=\right.$ $80)=20.12, p<.001]$, and likewise in Experiment 2 for both drawing errors $\left[\chi^{2}(1, n=91)=18.39, p<.001\right]$ and forced-choice errors $\left[\chi^{2}(1, n=91)=17.55, p<\right.$ $.001]$. The male advantage was also evident for the experts tested in Experiment 3, for both drawing errors $\left[\chi^{2}(1, n=\right.$ $64)=13.86, p<.001]$ and forced-choice errors $\left[\chi^{2}(1\right.$, $n=64)=9.98, p<.01]$.

One reason for this male advantage may be that most men have had more experience overall with bicycles, even those who rarely or never cycle. The results of the questionnaire provided some evidence for this. In the first two experiments, men reported slightly higher levels of cycling, and in all three experiments men stated that they repaired bicycles more than women did. However, no difference was found between the performance of males in

Table 2

Self-Ratings of Functional Knowledge Provided Before and After Completing the Bicycle Tasks in Experiments 1, 2 and 3, and Correlations Between These Pretest and Posttest Ratings and Total Errors on the Frame, Pedals, or Chain Across Both the Drawing and Forced-Choice Tasks*

\begin{tabular}{|c|c|c|c|c|c|c|}
\hline \multirow[b]{2}{*}{ Rating Type } & \multicolumn{2}{|c|}{ Experiment 1} & \multicolumn{2}{|c|}{ Experiment 2} & \multicolumn{2}{|c|}{ Experiment 3} \\
\hline & Rating & Correlation & Rating & Correlation & Rating & Correlation \\
\hline Pretest & 4.6 & -.43 & 4.2 & -.36 & 5.4 & -.35 \\
\hline Posttest & 4.5 & -.48 & 4.0 & -.32 & 5.6 & -.29 \\
\hline Change & -0.1 & - & -0.2 & - & +0.2 & - \\
\hline
\end{tabular}

Note-Negative correlations indicate that people who rated their functional knowledge as good generally made fewer errors in the bicycle test. Self-ratings ranged from 1 (little or no knowledge) to 7 (thorough knowledge); see Figure 1. "Maximum of 6 errors. 
Table 3

Percentage Errors in the Bicycle Drawing and Forced-Choice Tasks in Experiments 1, 2, and 3 for Each Error Type (Frame, Pedals, and Chain) and Then If at Least 1 Error Occurred in Any of the Three Error Types, for Females and Males

\begin{tabular}{|c|c|c|c|c|c|c|}
\hline \multirow[b]{2}{*}{ Error Type } & \multicolumn{2}{|c|}{ Experiment $1^{*}$} & \multicolumn{2}{|c|}{ Experiment $2^{* *}$} & \multicolumn{2}{|c|}{ Experiment $3^{* * *}$} \\
\hline & Drawing & Forced Choice & Drawing & Forced Choice & Drawing & Forced Choice \\
\hline \multicolumn{7}{|l|}{ For Females } \\
\hline Frame & 16 & 42 & 30 & 58 & 11 & 11 \\
\hline Pedals & 9 & 5 & 13 & 6 & 17 & 11 \\
\hline Chain & 56 & 44 & 63 & 52 & 17 & 28 \\
\hline Any & 65 & 63 & 75 & 70 & 28 & 28 \\
\hline \multicolumn{7}{|l|}{ For Males } \\
\hline Frame & 8 & 8 & 8 & 21 & 0 & 2 \\
\hline Pedals & 5 & 3 & 4 & 4 & 0 & 0 \\
\hline Chain & 14 & 11 & 21 & 21 & 0 & 0 \\
\hline Any & 22 & 14 & 25 & 21 & 0 & 2 \\
\hline
\end{tabular}

Note-1, 3, and 4 participants in Experiments 1, 2, and 3, respectively, did not specify their gender, so their results are not included here. $\quad{ }^{*}$ Females, $n=43$; males, $n=37 . \quad{ }^{* *}$ Females, $n=67$; males, $n=$ 24. ${ }^{* * *}$ Females, $n=18$; males, $n=46$.

Experiments 1 and 2 and that of females in Experiment 3, either for drawing errors $\left[\chi^{2}(1, n=79)=0.18, p>.6\right]$ or for forced-choice errors $\left[\chi^{2}(1, n=79)=1.17, p>.2\right]$. This provides evidence that the male advantage was not solely due to men having greater experience with bicycles, since these nonexpert males reported much lower levels of cycling than did the expert women and similar levels of experience at repairing bicycles. An alternative possibility is that men may generally have a better causal and functional understanding of objects due to innate or environmental differences between the sexes (see, e.g., Crowley, Callanan, Tenenbaum, \& Allen, 2001; Johnson, Alexander, Spencer, Leibham, \& Neitzel, 2004; Robert \& Harel, 1996).

The age of the participants had little influence on performance. Across Experiments 1 and 2, for young females $(n=75$; mean age $=18$; age range $17-28), 71 \%$ made drawing errors and $63 \%$ made forced-choice errors. Similarly high error rates occurred for older females $(n=34$; mean age $=47$; age range $40-54$ ), with $71 \%$ making drawing errors and $76 \%$ making forced-choice errors. Far fewer errors were made by young males $(n=28$; mean age $=18$; age range $17-23$ ), with $21 \%$ making drawing errors and $14 \%$ making forced-choice errors. Similarly low error rates occurred for older males $(n=33$; mean age $=50$; age range $42-63$ ), with $24 \%$ making drawing errors and $18 \%$ making forced-choice errors.

The questionnaire results revealed that 30 of the 175 nonexperts in Experiments 1 and 2 cycled at least monthly, whereas 7 of the 68 experts tested in Experiment 3 cycled less than weekly. The results of these participants were, nevertheless, similar to those of the remainder of the participants in each experiment, so they do not alter the conclusions drawn above.

\section{GENERAL DISCUSSION}

Many of the nonexperts tested in the first two experiments revealed major inaccuracies and omissions in their understanding of how bicycles worked, despite almost all of them having learned to ride a bicycle and nearly half of them owning a bicycle; and despite bicycles being common, everyday objects. When objective assessments were made, serious errors of functional understanding of bicycles were found to be common. Performance improved - but was still not perfect - for bicycle experts (in Experiment 3) and for nonexperts shown a real bicycle to copy (see note 1).

It would be unsurprising if nonexperts had failed to explain the intricacies of how gears work or why the angle of the front forks of a bicycle is critical. Indeed, even physicists disagree about seemingly simple issues, such as why bicycles are stable (Jones, 1970; Kirshner, 1980) and how they steer (Fajans, 2000). What is striking about the present results is that so many people have virtually no knowledge of how bicycles function. For example, many people (but especially women) cannot specify the correct position of the bicycle pedals and chain. They do not appear to understand a simple set of causal relations (turning the pedals turns the chain that spins the back wheel that drives the bicycle forward); therefore, they do not know how turning the pedals moves a bicycle. These findings now need to be extended to a range of everyday objects to establish the generalizability of the present results.

The failures in understanding demonstrated in the present study reveal that most people's functional understanding of bicycles is sketchy and shallow (see Keil, 2003b; Wilson \& Keil, 2000). The present study concentrated on measuring functional knowledge objectively, so it complements Rozenblit and Keil's (2002) studies (which focused on measuring changes to subjective self-ratings). Together, these results suggest that people have a vague, fragmentary, and often inaccurate understanding of how many everyday objects function. The weakness in people's knowledge is particularly striking for mechanical objects with visible parts, such as bicycles (Rozenblit \& Keil, 2002).

Keil (2003b) has argued that a minimal, superficial understanding of function may actually benefit us by letting us efficiently interpret the world and make accurate causal predictions without overburdening our limited processing 
and storage capabilities. People may overestimate their understanding of how objects work because they do not realize how reliant they are on extracting perceptual information directly from the world rather than from memory (see note 1).

Similarly, Norman (2002) has argued that everyone forms theories about how everyday objects function to explain what they have observed. Norman, however, suggests that these explanations may be based on weak, fragmentary, or even inaccurate evidence. One example involves the room thermostat. People often try to quickly heat up a room by turning the thermostat all the way up. Norman suggests that this is because they have an incorrect explanation for how the thermostat works. He notes, "In the case of the thermostat, the design gives absolutely no hint as to the correct answer. In the absence of external information, people are free to let their imaginations run free" (p. 39). The present findings are more surprising, for they suggest that we may not acquire an understanding of how an object such as a bicycle works even if the necessary information is readily available in our everyday environment (see note 1). We may only rarely try to provide explanations or to test the consistency of our fragmented understanding of the world (Leiser, 2001).

If we usually store only relatively superficial and fragmentary information about even the most familiar objects in our environment (Keil, 2003b; Norman, 2002); if we do not understand the basics of how common objects work (Rozenblit \& Keil, 2002); if we rarely try to provide explanations of object function; and if we do not test the consistency of our knowledge (Leiser, 2001); then the role of explanations and theories in our understanding of everyday concepts may need to be reexamined. Explanation-based (or theory-based) theories of categorization emphasize that relatively high level, sophisticated causal theories underpin our concepts and that such theories are important in everyday behavior (Ahn \& Luhmann, 2005; Murphy, 2002; Murphy \& Medin, 1985). The proponents of strong versions of explanation-based theories have gone further. For example, Brewer, Chinn, and Samarapungavan (1998) have suggested that children and adults both develop theories about concepts - theories that are similar to scientific explanations. Chaigneau, Barsalou, and Sloman (2004) have stated that "as common artefacts are encountered repeatedly, especially during development, people explore the underlying causal mechanisms to understand their functions. As a result, causal models become established in memory to represent these understandings" (p. 620). Yet these claims are not supported by the present results; it is now important to establish whether the present findings extend to other objects.

In contrast, others who support explanation-based theories of categorization have stressed the limitations of people's explanations (Keil, 2003b; Rozenblit \& Keil, 2002). Keil (2003a) has suggested that often only mundane, general knowledge - not sophisticated, domainspecific information - may be available to us (e.g., that objects given the same name have similar properties; that all animals have roughly the same internal parts; that off- spring grow up to look like their parents). Murphy (2002) has warned that "if explanations are often applied after the fact and are rather shallow, then how helpful could they be in using a concept? . . It is possible that the limitations on our knowledge will make it less than useful in many cases. Among those cases would be situations in which knowledge is incomplete or partially wrong, unfortunately not unusual circumstances for humans" (p. 145). The present findings support these cautious views. It seems clear that people do sometimes use prior knowledge when they categorize (Kaplan \& Murphy, 2000; Lin \& Murphy, 1997; Palmeri \& Blalock, 2000; Wisniewski, 1995). These cases may be exceptions, however. General background information might be useful for difficult categorization tasks that have relatively sparse category information (e.g., short verbal descriptions or simple depictions of stimuli). Under most circumstances, though, our categorization processes may rely primarily on information that is simple and largely perceptual. Even induction and category learning may not usually make use of functional or causal information (Murphy, 2002). These suggestions are, however, necessarily speculative: Explanation-based theories are relatively recent and have not yet been extensively tested. More empirical research is needed to clearly establish the role played by functional and causal information in our conceptual knowledge across a range of tasks.

The present results are unexpected, even on accounts of categorization that emphasize the perceptual basis of conceptual knowledge. The bicycle frame, chain, and pedals are large, readily perceived parts. Correctly locating them is easy if a bicycle is visible (see note 1). Even if only visual information about bicycles was stored, the errors observed in Experiments 1 and 2 should not have occurred. Bicycles are visually distinctive, with no close neighbors in shape space (toy scooters have no frame and much smaller wheels; motorbikes and mopeds have bulkier frames and an engine). Since it is unnecessary to store detailed information about bicycle shape in order to distinguish bicycles from other similar objects, our stored visual representations of bicycles may themselves be sketchy. People have been found to have surprisingly poor perceptual memory for everyday objects such as coins (Nickerson \& Adams, 1979) and road signs (Martin \& Jones, 1998). Marmie and Healy (2004; see also Rinck, 1999) found that recall of the features of coins and their spatial position was much improved after just $15 \mathrm{sec}$ of intentional learning and that intentional study produced large benefits, even when recall was delayed by one week. Their results suggest that reports of strikingly poor memory for common objects (e.g., Martin \& Jones, 1998; Nickerson \& Adams, 1979) are due to people's failure to encode information because it is not useful for the everyday use of the objects (e.g., knowing the direction that a head faces on a coin). This suggests that little detailed visual information may be stored following incidental learning of even highly familiar objects. Note, however, that most of the information tested in these studies had no functional significance. In contrast, a bicycle 
with pedals attached directly to the front wheel or with a chain around both wheels would no longer function as a normal bicycle. Nevertheless, the present results indicate that even this functionally important and perceptually salient information is often not readily available to people.

A personal anecdote illustrates this last point. I regularly scuba dive, and on one weekend trip two friends and I decided to do a night dive. We needed our weight belts, which were on a boat in the harbor, so I offered to fetch them. I swam the few meters to the boat in my dry suit, clipped my own weight belt around my waist, held one weight belt in each hand, slipped overboard, and headed back to the ladder. To my surprise, I immediately sank to the bottom of the harbor. I flailed up and managed to gasp some air but could not move forward before I was dragged down again. Realizing that I was well on my way to drowning, I dumped the two loose weight belts and managed to reach the ladder. In retrospect, the mistake was shocking. I have spent years carrying lead weight belts around: Their heaviness is both perceptually highly salient and central to their function. I had tried to carry three people's weight belts, even though I knew that my own weight belt was adjusted to make me only just buoyant in a dry suit. Why, then, did I fail to anticipate what would happen when I jumped into the water carrying enough lead to sink me, no matter how hard I swam? My conceptual knowledge of weight belts let me understand what had happened after the event, but it was not until the physical constraints of the real world impinged that I accessed this information. Such post hoc explanations created after perceptual experiences allow us to learn from our mistakes but otherwise may have little influence on our everyday actions.

The present findings indicate people's striking inability to remember the location of three causally critical parts of a common object: the bicycle. Many people do not appear to store accurate concept-specific information about causal function (e.g., that the pedals of a bicycle drive a chain around that drives the back wheel forward). Most people's conceptual knowledge of this everyday object seems to bear little resemblance to a scientific theory. The present results are not consistent with those of strong versions of explanation-based theories, which propose that high-level, domain-specific causal and functional information is central to our conceptual knowledge. Instead, people may rely largely on relatively simple, concept-general information (e.g., that objects given the same name usually have the same shape but often differ in color and size, or that all animals have roughly the same parts inside them; Keil, 2003a).

\section{REFERENCES}

Ahn, W.-K., \& Luhmann, C. C. (2005). Demystifying theory-based categorization. In L. Gershkoff-Stowe \& D. H. Rakison (Eds.), Building object categories in developmental time: Carnegie Mellon Symposia on cognition (pp. 277-300). Mahwah, NJ: Erlbaum.

Bertamini, M., Spooner, A., \& Hecht, H. (2003). Naive optics: Predicting and perceiving reflections in mirrors. Journal of Experimental Psychology: Human Perception \& Performance, 29, 982-1002.
Brewer, W. F., Chinn, C. A., \& Samarapungavan, A. (1998). Explanation in scientists and children. Minds \& Machines, 8, 119-136.

CAREY, S. (1985). Conceptual change in childhood. Cambridge, MA: MIT Press.

Chaigneau, S. E., Barsalou, L. W., \& Sloman, S. A. (2004). Assessing the causal structure of function. Journal of Experimental Psychology: General, 133, 601-625.

Crowley, K., Callanan, M. A., Tenenbaum, H. R., \& Allen, E. (2001). Parents explain more often to boys than to girls during shared scientific thinking. Psychological Science, 12, 258-261.

Dunning, D., Johnson, K., EhrLinger, J., \& KRUGer, J. (2003). Why people fail to recognize their own incompetence. Current Directions in Psychological Science, 12, 83-87.

FAJANS, J. (2000). Steering in bicycles and motorcycles. American Journal of Physics, 68, 654-659.

Johnson, K. E., Alexander, J. M., Spencer, S., Leibham, M. E., \& NeITZEL, C. (2004). Factors associated with the early emergence of intense interests within conceptual domains. Cognitive Development, 19, 325-343

Jones, D. E. H. (1970). The stability of the bicycle. Physics Today, 23, 34-40.

Kaiser, M. K., Proffitt, D. R., Whelan, S. M., \& Hecht, H. (1992). Influence of animation on dynamical judgments. Journal of Experimental Psychology: Human Perception \& Performance, 18, 669-689.

KAPLAN, A. S., \& MURPHY, G. L. (2000). Category learning with minimal prior knowledge. Journal of Experimental Psychology: Learning, Memory, \& Cognition, 26, 829-846.

KEIL, F. C. (1989). Concepts, kinds, and cognitive development. Cambridge, MA: MIT Press.

KeIL, F. C. (2003a). Categorisation, causation, and the limits of understanding. Language \& Cognitive Processes, 18, 663-692.

KeIL, F. C. (2003b). Folkscience: Coarse interpretations of a complex reality. Trends in Cognitive Sciences, 7, 368-373.

KIrShner, D. (1980). Some nonexplanations of bicycle stability. American Journal of Physics, 48, 36-38.

LEISER, D. (2001). Scattered naive theories: Why the human mind is isomorphic to the Internet web. New Ideas in Psychology, 19, 175-202.

Lin, E. L., \& MurPhy, G. L. (1997). Effects of background knowledge on object categorization and part detection. Journal of Experimental Psychology: Human Perception \& Performance, 23, 1153-1169.

MABE, P. A., III, \& WeST, S. G. (1982). Validity of self-evaluation of ability: A review and meta-analysis. Journal of Applied Psychology, 67, 280-296.

MARMIE, W. R., \& Healy, A. F. (2004). Memory for common objects: Brief intentional study is sufficient to overcome poor recall of US coin features. Applied Cognitive Psychology, 18, 445-453.

Martin, M., \& Jones, G. V. (1998). Generalizing everyday memory: Signs and handedness. Memory \& Cognition, 26, 193-200.

Mills, C. M., \& KeIL, F. C. (2004). Knowing the limits of one's understanding: The development of an awareness of an illusion of explanatory depth. Journal of Experimental Child Psychology, 87, 1-32.

MurPhy, G. L. (2002). The big book of concepts. Cambridge, MA: MIT Press.

Murphy, G. L., \& Medin, D. L. (1985). The role of theories in conceptual coherence. Psychological Review, 92, 289-316.

Nickerson, R. S., \& ADAMS, M. J. (1979). Long-term memory for a common object. Cognitive Psychology, 11, 287-307.

Nobes, G., Martin, A. E., \& PANAGiotaKi, G. (2005). The development of scientific knowledge of the Earth. British Journal of Developmental Psychology, 23, 47-64.

NoRman, D. A. (2002). The design of everyday things. New York: Basic Books.

O'REgan, J. K. (1992). Solving the "real" mysteries of visual perception: The world as an outside memory. Canadian Journal of Psychology, 46, 461-488.

PaLmeri, T. J., \& B LALOCK, C. (2000). The role of background knowledge in speeded perceptual categorization. Cognition, 77, B45-B57.

PAZZANI, M. J. (1991). Influence of prior knowledge on concept acquisition: Experimental and computational results. Journal of Experimental Psychology: Learning, Memory, \& Cognition, 17, 416-432. 
Proffitt, D. R., Kaiser, M. K., \& Whelan, S. M. (1990). Understanding wheel dynamics. Cognitive Psychology, 22, 342-373.

RINCK, M. (1999). Memory for everyday objects: Where are the digits on numerical keypads? Applied Cognitive Psychology, 13, 329-350.

Robert, M., \& Harel, F. (1996). The gender difference in orienting liquid surfaces and plumb-lines: Its robustness, its correlates, and the associated knowledge of simple physics. Canadian Journal of Experimental Psychology, 50, 280-314.

ROHRER, D. (2003). The natural appearance of unnatural incline speed. Memory \& Cognition, 31, 816-826.

RozENBLIT, L., \& KeIL, F. [C.] (2002). The misunderstood limits of folk science: An illusion of explanatory depth. Cognitive Science, 26, 521-562.

Smith, E. E., \& Sloman, S. A. (1994). Similarity- versus rule-based categorization. Memory \& Cognition, 22, 377-386.

WiLSON, R. A., \& KeIL, F. C. (2000). The shadows and shallows of explanation. In F. C. Keil \& R. A. Wilson (Eds.), Explanation and cognition (pp. 87-114). Cambridge, MA: MIT Press.

WisNiEWSKI, E. J. (1995). Prior knowledge and functionally relevant features in concept learning. Journal of Experimental Psychology: Learning, Memory, \& Cognition, 21, 449-468.

\section{NOTE}

1. A final experiment replicated the results of Experiment 1 and tested 58 nonexperts from the same population as Experiments 1 and
2 , but people could copy from a real bicycle as they completed the questionnaire. O'Regan (1992) suggested that we may be using the world as an "outside memory" to save us from having to store huge amounts of information. Since much of the information that we need in everyday life can be found simply by moving our eyes, we do not need to store it and then retrieve it from memory (Norman, 2002). If so, people shown a bicycle should succeed at the task. This hypothesis was supported. Relative to those tested in Experiment 1, many fewer nonexperts made drawing errors $\left[\chi^{2}(1, N=139)=12.92, p<.001\right.$; mean errors $=16 \%]$ or forced-choice errors $\left[\chi^{2}(1, N=139)=12.61\right.$, $p<.001$; mean errors $=12 \%]$. Indeed, these nonexperts who could copy a real bicycle made no more errors than did the experts tested in Experiment 3, either in their drawing $\left[\chi^{2}(1, N=126)=1.34, p>\right.$ .2] or in the forced-choice task $\left[\chi^{2}(1, N=126)=0.04, p>.8\right]$. The errors in Experiments 1 and 2 were thus not due to participants failing to understand the task or to their misinterpreting the bicycle sketch, nor were most errors due to their inability to draw or to their lack of motivation. The accuracy of nonexperts who were shown a real bicycle demonstrates that the information needed to succeed at the task is commonly available in people's everyday lives.

(Manuscript received June 21, 2005; revision accepted for publication August 24, 2005.) 